\title{
COVID-19: Las TIC y la ruptura del velo de la desigualdad social en la Educación
}

\author{
COVID-19: ICTs, Tearing the veil of social inequality in \\ Education
}

Lucía Anderson $\square^{\natural}$ (D) Gricel Martínez (iD) Diana Londoño

Universidad Metropolitana de Educación, Ciencia y Tecnología. Ciudad de Panamá, Panamá

Recibido: $12 / 12 / 2021 \quad$ Revisado: 16/12/2021 Aceptado: 25/12/2021 Publicado: 15/01/2022

\section{RESUMEN}

La crisis generada por la pandemia del COVID-19 ha afectado a la sociedad en diferentes áreas, dejando pérdidas a nivel social, económico y especialmente en el ámbito educativo. El efecto más claro que se ha develado durante la crisis, han sido las debilidades de las políticas educativas, no solamente a nivel nacional sino a nivel mundial. Lo anterior ha sido el resultado de la gran desigualdad económica de los grupos sociales frente al proceso educativo y muy particularmente al acceso a la tecnología. La vulnerabilidad y la desigualdad social se hicieron aún más latentes en esta crisis mundial, siendo, una vez más, los grupos desfavorecidos los más afectados. El enfoque de este artículo es desglosar la visión clara del impacto causado por la pandemia del COVID-19 y el efecto desolador que ésta dejó, especialmente en aspectos relacionados con la convivencia humana. Aunque el mundo se haya transformado con la aparicion de las TIC y la idea de conectividad que se ha generado a nivel mundial, produce una sensación de cercanía, no ha sido más que un espejismo bajo el cual se ha ocultado la negligencia con la que se ha manejado tanto el sistema gubernamental, como el educativo. La necesidad de ejecutar cambios con el fin de generar una educación igualitaria para aquellos que no gozan de poder económico es, sin lugar a dudas, una prioridad. Palabras clave: TIC, desigualdad, pandemia, educación, brecha, vulnerabilidad.

\section{ABSTRACT}

The COVID-19 crisis has wounded society in different areas, such as social, economic, but particularly, the educational field as a result, of the great economic inequality of social groups in the face of the educational process and, particularly, access to technology. The clearest effect revealed during the crisis is the weaknesses of educational policies, not only at the national level, but also at the global level. Vulnerability and social inequality became even more latent in this global crisis, with disadvantaged groups being, once again, the most affected. The purpose of this article is to examine the bleak effect of the Covid-19 pandemic, espe- 
cially as it relates to humanity's coexistence. Although the appearance of ICT has transformed and connected us on a worldwide level, producing a feeling of closeness, this has only been a mirage which disguises negligence on both a governmental level as well as an educational level. The need for changes to generate an egalitarian educational system-- one which doesn't economically favor some over others-- is, without doubt, a priority. Keywords: ICT, inequality, pandemic, education, gap, vulnerability.

\section{INTRODUCCIÓN}

La desigualdad ha estado presente en la sociedad desde sus inicios. Son muchos los intentos que se han dado a través de la historia para aminorar las inequidades sociales; sin embargo, el pasar de los años ha creado una barrera que inhibe ver el contexto real por el que pasan las diferentes poblaciones. El propósito de este artículo es hacer un análisis crítico de la disparidad que se generó a nivel educativo, tecnológico y social, a raíz del cierre de las instituciones educativas por causa de la pandemia originada por el COVID-19. A principios del año 2020 el mundo entero se vio enfrentado a uno de los virus con mayor índice de mortalidad en los últimos tiempos, el cual registra para el mes de mayo del 2021, de acuerdo con Statista (2021), alrededor de 3,74 millones de personas fallecidas a causa de la pandemia. Ésta, que también es conocida como coronavirus, es un virus silencioso, invisible e intangible, capaz de causarle la muerte a cualquier persona, en particular a aquellas que poseen condiciones preexistentes de salud o edades avanzadas. Para la Organización Mundial de la Salud (La OMS caracteriza al COVID-19 como una pandemia, 2020), el nivel de propagación y gravedad de la enfermedad hizo que fuera declarada pandemia a nivel mundial el 10 de marzo del 2020. Con la llegada de este patógeno a nivel global la humanidad tuvo que asumir retos inimaginables y generar alternativas sociales, especialmente en los aspectos relacionados con la educación. Es en este momento cuando los colectivos necesitan redefinirse y generar nuevas politicas que incluyan a todos equitativamente.

La pandemia del COVID-19 ha desembocado en diferentes problemáticas que han marcado el presente milenio de manera devastadora. En primera instancia, el desbalance económico, el desempleo, las pérdidas monetarias y la caída de los mercados financieros, ha traído al límite la capacidad de respaldo por parte de los gobiernos a nivel mundial. En segundo lugar, el gran abismo que ha dejado al descubierto la falta de acceso tecnológico en el campo educativo, vinculado directamente al déficit económico de los grupos sociales, ha marcado una diferencia insondable entre los grupos de estudiantes económicamente solventes y aquellos que no lo son. Finalmente, la falta de preparación de los entes educativos para afrontar los nuevos retos de la enseñanza a través de las TIC, ha puesto en jaque al sistema educativo y a su capacidad de respuesta frente a las necesidades de los sectores sociales en condiciones de riesgo.

\section{DESARROLLO}

Este virus ha puesto a la raza humana en total estado de vulnerabilidad, cambiando, la cotidianidad del ser humano, sus interacciones sociales y las prácticas culturales más superficiales. El contacto físico, hablar con el otro, mostrar el rostro, reunirse con amigos y coexistir en comunidad, son hoy en día un privilegio. El COVID-19 no solo ha traído transformaciones en el núcleo del hogar, sino 
que ha puesto a las naciones en un estado de emergencia que las ha forzado a tomar decisiones y desarrollar estrategias en el área social, económica y educativa. Todo esto, con miras a permitir la superación de la crisis de salud pública; que ya ha afectado severamente a los grupos sociales más vulnerables como niños, adultos mayores, personas en situación de discapacidad e inmigrantes; entre otros.

Por otro lado, la pandemia ha evidenciado no sólo la disparidad social, sino las falencias del sistema educativo referente al manejo de las TIC y la falta de capacitación docente en las mismas; tres grandes problemáticas que han generado un desfase en el avance socioeducativo de muchos países. El COVID-19 no hace distinción entre clases o niveles de educación, pero sí ha logrado desmantelar el engranaje de estos, atacando a la sociedad desde más ángulos de los que se pueden manejar. En consecuencia, según la (UNESCO, 2015), surgen interrogantes sobre garantías en la calidad, inclusión y equidad en el proceso de aprendizaje. Se espera que este cambio de rumbo intempestivo permita mejorar las normativas en la educación, ampliar el conocimiento de las TIC mediante capacitación, no solo para docentes sino para todos los ciudadanos, sin importar su grupo social, reduciendo la brecha de inequidad que se ha incrementado.

Después de un año y diez meses de la declaración oficial del COVID-19 como pandemia, ha salido a la luz la desigualdad que el virus ha ocasionado en las diferentes naciones del mundo. Dicha situación agrava las condiciones de crisis sociales, económicas y políticas preexistentes, poniendo a sus dirigentes en un estado de emergencia frente a la gestión de recursos que puedan ayudar a mitigar el impacto económico en la sociedad, especialmente de aquellos en riesgo.

Ulrich (1998) se refiere a la crisis como un legado de contingencias mundiales que ignoran los límites fronterizos y que no están siendo distribuidos de manera igualitaria. Boschiero (2019) declara que los inconvenientes que se presentan, afectan a las comunidades, de acuerdo con su nivel social y cultural y a la facultad que tienen de responder a dichos inconvenientes a través de planes de intervención. Este argumento explica la desigualdad marcada y evidente ante la pandemia. Ésta se empieza a materializar con la prontitud de cada estado por identificar el COVID-19, como un problema existente que demanda un actuar efectivo de las instituciones al servicio de la comunidad.

Desde la aparición del COVID-19, el mundo no volvió a ser el mismo, mucho menos la educación. Ésta, no quedó exenta a los cambios abruptos que se originaron a partir del brote de coronavirus. Sorpresivamente, los estudiantes no pudieron regresar a las aulas. En algunos países las escuelas han permanecido cerradas por varios meses en espera de que pronto se vuelva a la normalidad. Esto ha provocado que tanto las escuelas de enseñanza primaria y secundaria, así como las de nivel superior, hayan tenido que ingresar involuntariamente al mundo de la enseñanza virtual. El aislamiento físico decretado para impedir que se propagara el virus, dio campo a tratar de mantener la salubridad nacional a salvo, y al mismo tiempo generó en el ambiente escolar, la urgencia de garantizar que los estudiantes tuvieran acceso a la educación, obligando al sistema educativo a embarcarse en el mundo de la virtualidad por medio de la tecnolo- 
gía, la información y la comunicación (TIC).

Las TIC se refieren a una tecnología que permite desarrollar una comunicación pronta y efectiva, generando cambios en la manera como se adquiere la información, modificando e implementando nuevos usos de herramientas digitales. La innovación y creación han llegado a tal escala, que las redes se multiplican para dar mayor alcance al intercambio de datos e información, al cual, Levi (2007) llamó la cibercultura. Estas tecnologías facilitan el proceso de enseñanza-aprendizaje, a través del intercambio rápido de información, de su incorporación como herramienta dentro del plan curricular, con el fin de posibilitar la obtención y el seguimiento de las competencias TIC. Se espera que el uso de estas herramientas, en el contexto de aula, esté acorde a las destrezas y habilidades tecnológicas que posea cada estudiante. En consecuencia, las TIC deben transformarse en el puente por medio del cual el educando adquiere nuevo conocimiento tecnológico, a la vez que se relaciona con otras áreas del saber.

Escobar y Mira (2019) exponen los cambios mundiales que han sucedido debido a la aparición de las TIC. Dichas herramientas han generado que la cultura y las relaciones interpersonales hayan dado un giro novedoso a nivel mundial, a la vez que se desarrollan situaciones adversas social y culturalmente. El COVID-19 puso a prueba el andamiaje de la educación pública y la inhabilidad que tiene de cubrir las necesidades de los estudiantes, entre estas el acceso de un inmenso número de discentes a la educación virtual. Aquellos que no poseen la facilidad de adquirir tecnología y que no tienen el conocimiento para usarla resultaron ampliamente afectados. Se puso en tela de juicio la equidad con que se debería manejar el uso y aprovechamiento de las TIC, especialmente a nivel educacional.

Ha sido en este momento en que la humanidad se encuentra abatida por una pandemia, que se puede dilucidar con claridad y sin temor a equivocarse, que la brecha digital, de la que habla Alva de la Selva, (2015) desemboca en la marginalización de grupos sociales frente al acceso, uso de las telecomunicaciones y las TIC; impidiéndoles integrarse a la nueva sociedad. Es no solo el poder conectarse a las redes, sino el hecho de cómo las personas generan o no interacción dentro de esta época cibernauta. Conexiones de provecho que les permitan continuar y mejorar su día a día. En este contexto de reflexión crítica frente al tema objeto la pregunta es ¿Hasta qué punto se está apoyando a los grupos sociales más abatidos para que la digitalización y las TIC sean un instrumento positivo de cambio y mejoramiento?

Ruano y Serrano (2014) enuncian que la brecha digital está ligada a dos variantes que son: el acceso a beneficios y la preparación de los ciudadanos para el uso de las TIC, de tal manera que aporten a la autosostenibilidad del grupo. Pero, ¿qué sucede cuando la población estudiantil se ve desprotegida y aislada sin poder conectarse con el exterior porque las TIC no llegan hasta sus hogares? Aparte de estar abatidos por el COVID-19, se encuentran segregados económica, política y socialmente, debido a la inequidad en que viven cada día. Al respecto, Sánchez (2020) agrega que este cambio abrupto de la educación presencial hacia la virtualidad trae consigo consecuencias que están estrechamente ligadas al nivel de educación.

La capacidad por parte de los estudiantes de manipular los recursos tecnológicos, su nivel de independencia para utilizarlos y 
la cantidad de recursos al alcance de ellos, son algunos de los factores determinantes en el éxito o no de la educación a través de las TIC. Cáceres-Muñoz y otros (2020) añaden a la lista de aspectos limitantes, que están fuera de control de los mismos estudiantes y maestros, la falta de alfabetización de los acudientes y la carencia de recursos tecnológicos en el núcleo familiar, decisivo al momento de apoyar al aprendiz desde la educación virtual.

Es importante resaltar que, una vez más la disparidad social se deja ver entre países desarrollados como Estados Unidos y aquellos en vía de desarrollo. Mientras que la mayoría de los estudiantes estadounidenses recibieron una computadora o tableta, y las escuelas adquirieron internet portable para los educandos que no contaban con conexión en sus casas, en otros países, como Colombia, los estudiantes no poseían los medios para vincularse a las clases virtuales o acceder en línea a materiales que el maestro había dispuesto para su aprendizaje.

En su análisis, Lopera-Zuluaga (2020), plantea una alternativa denominada-Aprender Digital- del Ministerio de Educación Nacional de Colombia; que consiste en una plataforma virtual de contenidos académicos que pueden ser accedidos de forma gratuita por toda la comunidad educativa, independientemente de la edad y nivel escolar. También pueden ser compartidos a través del correo electrónico, descargados y vinculados a las páginas web de las instituciones educativas. Esta propuesta buscaba contrarrestar el impacto de la cancelación de clases presenciales en instituciones públicas del país y lograr dar continuidad al proceso educativo, aún en época de coronavirus. Sin embargo, haciendo uso del eslogan -Contenido para Todos-, la ciudadanía dejó ver su inconformidad en las redes sociales, ex- presando su rechazo a la estrategia -Aprender Digital-, ya que esta solución tecnológica pone a las personas en condiciones de homogeneidad y da por hecho que todos los escolares se encuentran en igualdad de condiciones para embarcarse en el aprendizaje por medio de las TIC, siendo esto totalmente lo contrario.

Lopera-Zuluaga (2020) deja claro que, aunque la propuesta anterior busca innovar y favorecer a los estudiantes en su formación académica a través de la tecnología; ésta parece estar apuntando a una realidad social y económica de un país diferente a Colombia. Quedan al descubierto las diferencias abismales entre los estudiantes y maestros ubicados en la zona urbana y aquellos del área rural, donde aún los servicios básicos como luz y agua son de difícil acceso. Hablar del uso de herramientas TIC, es un tema ajeno a su realidad. El autor enfatiza que en época de COVID-19 se hace más evidente la desigualdad en términos de educación y acceso a las TIC; la cual, no solamente muestra la realidad educativa en Colombia, sino que en general, plasma las condiciones de acceso tecnológico de los países latinoamericanos.

Se necesita que las normativas generadas desde los estamentos gubernamentales, se centren en la realidad socio-económica de los estudiantes, sus familias, la facilidad de acceso y la capacitación de los ciudadanos con respecto al uso de las TIC. Esto, según Escobar y Mira (2019) incrementará la competencia crítica y reflexiva que permite el manejo de la información en internet. Hay que detener el aumento de esta disparidad educando a la sociedad, especialmente aquellos grupos menos favorecidos. Éstos, ya han sido relegados a nivel económico, social, político y ahora también se encuentran 
en desventaja frente a la aparición de las TIC.

No solamente son estudiantes y familias los afectados por el cambio abrupto al ámbito virtual de enseñanza. Zhou et al. (2020) describen la dificultad que han tenido los docentes al adaptar materiales, formas de comunicación, recursos audiovisuales y excesiva carga laboral. Lo anterior se añade a otros retos que desde antes de la pandemia ya se le imponían a la educación; como son las necesidades de grupos diversos y desarrollar niveles de aprendizaje favorables para los educandos. En este sentido, los docentes han tenido que hacer frente a la nueva realidad para que la educación sea accesible y significativa para cada uno de los estudiantes.

Dentro de sus posibilidades, los educadores han llegado a los lugares más recónditos para que todos los estudiantes continúen con su educación de manera "normal"; sin embargo, la labor ha sido ardua y difícil porque para muchos, el desconocimiento de la tecnología se ha convertido en un obstáculo que les impide lograr su cometido. En un abrir y cerrar de ojos el teletrabajo se transformó en la nueva vivencia, tanto para los educadores como para el estudiantado, misma para la que muchos no estaban preparados. Algunos pedagogos han aprovechado su manejo de las herramientas tecnológicas para ponerlo al servicio de los estudiantes. Otros, con un conocimiento básico han logrado llegar a los discentes y fortalecer sus habilidades tecnológicas. Aquellos que no poseían habilidades en el uso de las TIC, valientemente se han enfrentado a este mundo desconocido, temerosos pero movidos por el amor a la profesión docente y a los estudiantes. Es así como los educadores, entre tanta incertidumbre han sido capaces de demostrar entereza, valor y profesiona- lismo tomando control de lo desconocido.

Arancibia (2020 citado por Ferrada, V., González, N., Ibarra, M., Ried Donaire, A1., Vergara, D., Castillo, F., 2021) señala que, tanto profesores como estudiantes no poseen la preparación académica para interactuar en entornos educativos cibernéticos. Fernández (2015 citado por Ferrada, V., y otros, 2021) indica que es preocupante que, en la postmodernidad, dentro de la formación académica inicial de los educadores, el uso de las herramientas tecnológicas no esté incluido. De igual manera, para Hernández, (2018 citado por Ferrada, y otros., 2021) es necesaria la implementación de las herramientas tecnológicas en la capacitación docente, con miras a mejorar el desempeño del maestro y la integración de la tecnología en su labor. Se pretende con esto, que la falta de conocimiento y de preparación formal en el uso de las TIC durante una situación excepcional, no desestabilice el mundo de los docentes, provocando caos, incertidumbre, estrés y en algunos casos, ansiedad frente a lo desconocido. Esta vivencia debe ser una oportunidad para aprender el uso de las TIC, adaptarse a la realidad de enseñanza en igualdad de condiciones.

\section{CONCLUSIONES}

Las TIC han resultado un elemento indispensable en la impartición de los cursos escolares a pesar de las falencias evidenciadas. Es en este momento coyuntural para la humanidad y a causa del cierre colectivo de las instituciones educativas, que se vislumbra con mayor claridad, la necesidad del respaldo económico hacia el uso de las TIC.

Hay una falta de cobertura a sectores más desfavorecidos, la familia rural, los grupos indígenas y los niños y niñas 
en condiciones de pobreza. Las voces de aquellos que generalmente son acalladas por la desigualdad social podrán ser escuchadas y obtener los beneficios que representa el avance tecnológico en la educación.

La pandemia ha generado un desbalance para el que nadie estaba preparado, dando pie a la creación de planes de emergencia que han permitido resolver de manera superficial los nuevos inconvenientes.

El uso de las TIC, el impacto negativo que ha tenido la educación debido al cierre de las escuelas y los cambios abruptos por los que han pasado el profesorado, los estudiantes y sus familias, son temas de interés a nivel mundial que siguen generando preocupación
A causa del cierre de las escuelas se recurrió al uso de las herramientas digitales para facilitar la enseñanza-aprendizaje y se ha reconocido como prioridad la necesidad de capacitar a los docentes en el uso de las TIC.

A medida que se abren las escuelas y se embarcan en el nuevo derrotero educativo y social, se buscan soluciones enfocadas en la recuperación académica de los estudiantes, el bienestar de ellos y sus docentes. La experiencia adquirida para mejorar y resolver los retrasos sufridos en cada una de las instancias de vida del ser humano, y la ruptura del velo de la desigualdad social, se transforman en soluciones. Ya no es solo una entidad la responsable del cambio, ahora somos todos.

\section{REFERENCIAS BIBLIOGRÁFICAS}

Alva de la Selva, R. (2015). Los nuevos rostros de la desigualdad en el siglo XXI: la brecha digital. Revista Mexicana de Ciencias Políticas y Sociales, 60(223), 265-285. http://dx.doi.org/10.1016/S0185-1918(15)72138-0

Boschiero, E. (2019-2020). Riesgos globales y derechos humanos: hacia sociedades más resilientes, igualitarias y sostenibles. Anuario CEIPAZ 2019-2020,12(8),55-76. https://ceipaz.org/wp-content/uploads/2020/05/0.2020-ANUARIO-COMPLETO.pdf

Cáceres-Muñoz, J., Jiménez Hernández, A. S., y Martín-Sánchez, M. (2020). Cierre de Escuelas y Desigualdad Socioeducativa en Tiempos del Covid-19. Una Investigación Exploratoria en Clave Internacional. Revista Internacional de Educación para la Justicia Social, 9(3), 199-221. https://doi.org/10.15366/riejs2020.9.3.011

Escobar, J., y Mira, Y. (2019). La globalización y la importancia de las TIC en el desarrollo social. Reflexiones y Saberes, 11, 2-9. https://rb.gy/lnhrgm

Ferrada, V., González, N., Ibarra, M., RieDonaire, A., Vergara, D. y Castillo, F (2021). Formación docente en TIC y su evidencia en tiempos de COVID-19. Revista Saberes Educativos, 6, 144. DOI: 10.5354/2452-5014.2021.60715 
Flórez Romero, M., Aguilar Barreto, A. J., Hernández Peña, Y. K., Salazar Torres, J. P., Pinillos Villamizar, J. A., Pérez Fuentes, C. A. (2017). La sociedad del conocimiento, las TIC y su influencia en la educación. Revista Espacios.com, 38(35), 39-51. https://www.revistaespacios.com/a17v38n35/a17v38n35p39.pdf

La OMS caracteriza a COVID-19 como una pandemia. (2020 marzo 11).

OPS/OMS | Organización Panamericana de la Salud.

https://rb.gy/p60dps

Equipo Robotix, (17 de mayo del 2021). Las TIC en la educación. Blog de ROBOTIX. https://www.robotix.es/blog/las-tic-en-la-educacion/

Lévy, P. (2007). Cibercultura: la cultura de la sociedad digital (1st ed.). Anthropos Editorial. ISBN: 978-84-7658-808-6.

Lopera-Zuluaga, E. C. (2020). Réplicas en Redes Sociales que Denuncian Desigualdades de la Estrategia \#Aprender Digital en Tiempos de Covid-19. Revista Internacional de Educación para la Justicia Social, 9(3), 335-352. https://doi.org/10.15366/riejs2020.9.3.018

Ruano, J. J. y Serrano, J. C. (2014). Umbrales para la determinación de la brecha digital: comparativa entre regiones desarrolladas. Transinformación,125-132. https://doi.org/10.1590/0103-37862014000200002

Sánchez, M., Martínez, A., Torres, R., de Agüero, M., Hernández, A. K., Benavides, M. A., Rendón, V. J., y Jaimes, C. A. (2020). Retos educativos durante la pandemia de COVID-19: una encuesta a profesores de la UNAM. Revista Digital Universitaria, 21(3). https://doi.org/10.22201/codeic.16076079e.2020.v21n3.a12

Statista. (2021, 10 junio). COVID-19: número de muertes a nivel mundial por continente.2021. https://es.statista.com/estadisticas/1107719/covid19-numero-de-muertes-a-nivel-mundialpor-region/

Ulrich, B. (1998). La sociedad del riesgo. Hacia una nueva modernidad. España. ISBN: 84-4930406-7

UNESCO. (2015). Informe de seguimiento de la educación para todos en el mundo. La educación para todos, 2000-2015: Logros y desafíos. UNESCO. ISBN 978-9-233-00017-9 